Témoigner Témoigner. Entre histoire et mémoire

Getuigen Revue pluridisciplinaire de la Fondation Auschwitz

$118 \mid 2014$

Au nom des victimes. Dictature et terreur d'État en Argentine, Chili et Uruguay

\title{
Het beeld als getuigenis, het beeld als document
}

De quoi l'image est-elle le témoin?

What does the image testify to?

\section{Christophe Cognet}

\section{(2) OpenEdition}

\section{Journals}

\section{Édition électronique}

URL : http://journals.openedition.org/temoigner/1238

DOI : $10.4000 /$ temoigner. 1238

ISSN : 2506-6390

\section{Éditeur :}

Éditions du Centre d'études et de documentation Mémoire d'Auschwitz, Éditions Kimé

Édition imprimée

Date de publication : 1 octobre 2014

Pagination : $21-25$

ISBN : 978-2-84174-674-3

ISSN : 2031-4183

\section{Référence électronique}

Christophe Cognet, «Het beeld als getuigenis, het beeld als document », Témoigner. Entre histoire et mémoire [Online], 118 | 2014, Online op 01 octobre 2015, geraadpleegd op 23 octobre 2020. URL : http://journals.openedition.org/temoigner/1238; DOI : https://doi.org/10.4000/temoigner.1238 


\section{HET BEELD ALS GETUIGENIS, HET BEELD ALS DOCUMENT}

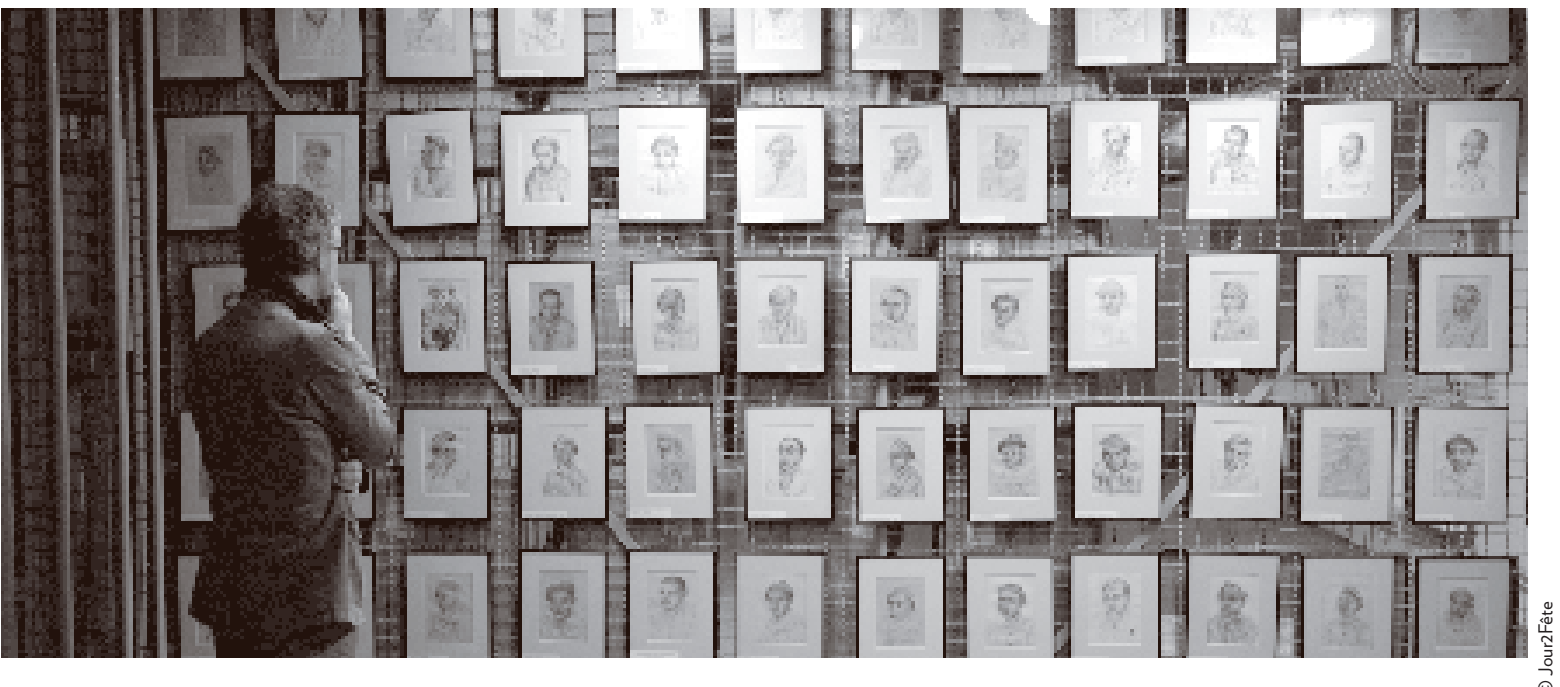

FILM In de nazikampen zijn een aantal gedeporteerden erin

geslaagd clandestien kunstwerken te maken. Filmmaker Cristophe

Cognet gaat op onderzoek uit naar de schier onmogelijke

omstandigheden waarin deze werken zijn ontstaan en naar de manier

waarop zij de realiteit van de concentratiekampen voorstellen. De

kunst, zo lijkt het wel, is hier meer dan alleen een getuigenis. 114 portretten die zijn gemaakt in Buchenwa Groß-Rosen, Auschwitz (1943-1945) Ze worden bewaard in het museum van

De kunstenaars die u heeft gesproken, zijn erg duiChristophe Cognet: Toen ik besefte dat het niet in film wilde maken. Het ging om iets anders, om een soort van urgentie. De schilders en tekenars maakten

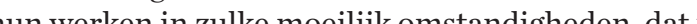
igenlijk nietvan zu De kunstens die in heb on De over is de datwas nieth o is de film dan kunnen ontstaan.

It ga ervan uit dat ik kunstwerken film, terwij men vroeger zou gezegd hebben dat het getuigenis- dimensie. Maar als het kunstwerken zijn, waarvan Detuigen ze dan, wam Wanner Boris Taslitzky ankomt in het Wanuld injuli 1944 is hij als schilder vanp van Buch Hij wordt vrijw wa delen va lets in in delen van het kanp. De interne verzetseweging, die cur kamp en de leiding heeft over een deel van de adminisgatien breng hapier getuigen. Maar Bors heeft altija gezegd dat hij geen 
. kunstenaar zijn en de andere dag getuige; hij is alle dagen kunstenaar en alles wat hij maakt, behoort to zijn oeuvre.

Een tweede voorbeeld: in de concentratiekampen werden enorm veel portretten gemaakt van medegeangenen. Er waren geen spiegels, of toch heel weinig. Wie een beeld wilde hebben van zichzelf of een spoo van zichzelf wilde nalaten, zocht een kunstenaar die con den achteraf dat ze de portretten niet helemaal waarheidsgetrouw tekenden, zodat hun kameraden er op papier niet zouden uitzien als levende lijken. Als wij en die zroblem is met de getuigenis. we zien beelden die zijn bewerkt. Als er van die mensen een fo Ik heb het darom

Inen gver 'docis docume soren, overbijfselen van de kampen. Als je de tekein is is documentatiemateriaal. Het bewijst dat papieren

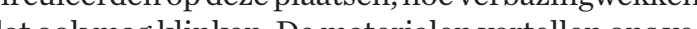
dat ook mag klinken. De materialen vertellen ons veel meer over derealiteit vandekampen dan bijvoorbeeld een portret dat op een achterkantje is gekrabbeld, of

De beelden roepen no een andere vraag op: wat weten we over hun auteurs, over de omstandighede waarin ze zijn gemakt en beward? Ook daar is het idee van getuigenis erg pioblematisch, omdat vaa

Nogbijzonder aan de tekeningen - en dat is werkelijk een uitgelezen onderwerp om in een film te behandelen - is het standpunt. Hebben de tekenaars zelf gezien wat ze tekenen? Een bekend voorbeeld dat niet uit de Plmkomt, is de papieren sculptuur Tunnel die Edmund Palch schrijver dan een plastisch kunstenaar. Op elke zijd ande tekeningen staat een gedicht. Uit onderzoek is heft hij dat kunsterk heeft hij dat kinstwe nissen van viendend

Dan hebje nog de tekeningen van binnenin de gaskamers. Zo zijn er heel weing. Dat is natuurlijk ee onmogelijk standpunt.

, het schetsboek dat we ook in de film zien, is misschien een soort van getuigenis,

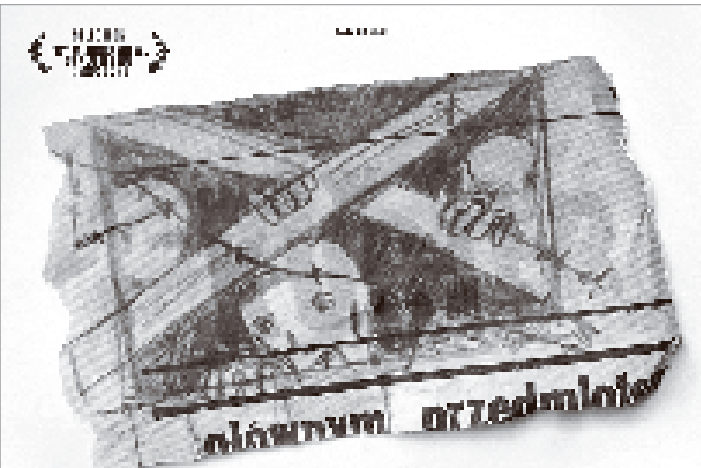

\section{Parce que j’étals peintre \\ L'arl rescape des camps nazis}

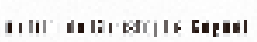

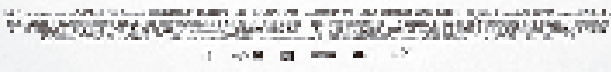

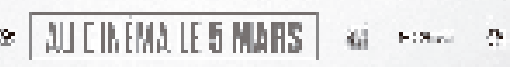

omdat het een beetje doet denken aan de tekeningen die in de kranten verschenen. We weten niet wie de auteur is. Het boekje werd gevonden in het verste deel van het kamp, het 'hospitaal', net naast de 'Canada' en in het gebied en V. Maar blijkbaar is de auteur niet in het gebied geweest waar de gevangenen werden getoond. De tekeningen van Yehuda Bacon werden getoond tijdens het proces tegen Eichmann. Het is een medium om te getuigen. Alleen met tekeningen kan je niets bewijzen, maar het kan een manier zijn om te
communiceren.

Een opmerkelijke passage in de film is het moment waarop Samuel Willenberg getuigenis aflegt op basis van zijn kunst.

Christophe Cognet: Dat klopt. Aan alle mensen die ik heb ontmoet, heb ik gevraagd of ze een tekening wilden maken die hun ervaring weergaf. Drie hebben da gedaan. 'Heeft de hand een geheugen?', vroeg ik me af Ik nam de spullen van Willenberg mee naar Treblinka op zijn vraag. En hij begon te tekenen zonder elkaar, ik zag niet wat het moest voorstellen. Wat ik zo interessant vond, was dat hij een beeld maakte dat zo interessant vond, was dat hij een beeld maakte dat de onmogelijkeid wan het beeld illustreerde. Want keste afbeelden, maar je kan welde onmogelijkheid van de afbeelding voorstellen. De film is voortdurend op zoek

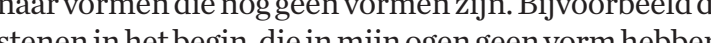
dat vind ik jes dation jes, dat is het meest aangrjpende menoriaal dat ik ooit

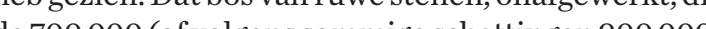
de

akte, dacht ik ik begrijp er niets van, ik weet niet hoe ik dit moet interpretern. Hij zei no: 'Mark dit stelt het moment voor waarop ik ben ontsapt.' En achteraf, vier of vijf beeldhouwwerk [datlijkt op de tekning] toont hij zijn on we in de we in de tekning het nonent zien dat ervor heeft gezorgd dathijkon overleven, en dus ook dat hij me kan

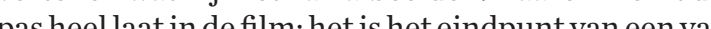
pas heel wat inde film: hetis heteind Dunt van een van de vian wardeling

Ikgeloof niet in dogma's daaromtrent, in tegenstehe colleanzis de collecties in Ru An han die in Isrël, de VS enk dat ik een goed idee heb van die in Israel, de VS en Westheft. - moet ik toch zeggen dat Lanzmann gelijk melijk is van binnenuit, vanuit de gaskamer en mogelijk is van binenuit, vanuit de gaskamer en de praktische, en vermoedelijk thische redenen Jer on praktische, enver

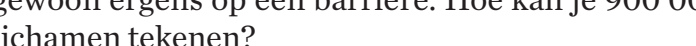

Uhad het meermaals over 'sporen'. Voelen de kunstenaars ergens de behoefte om een spoor achter te laten? Christophe Cognet: Voor mij draait de film ook werkelijk om sporen. Als je een film maakt over zo'n onderwerp, moet je volgens mij het beeld bestuderen a ich toch altijd anders, Uitering ter toch altijd anders, naargelang het materiaal dat hij ter besch 34 ing hect. Boris was in de wolken toen hij in bar de kiezels, de papieren, de geluiden. Er zitten klanken in het materiaal. Ik heb de 5.1-opname bewerkt en he geluid soms uitgerekt of gecomprimeerd. Tijdens het draien wille ik een dubbele stereofonische geluidsper viff microfoons (warvan én gentrele,

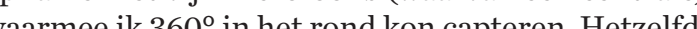
Wer . kkon de elden in een nieuw, actueelkater. iijn bedoeling om de beelden en de geludenterecon te zie hoe wij ons zoals ze vroeger waren, maar on

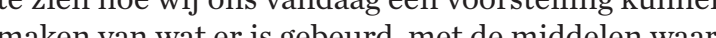
over we op dit moment beschikken, zonder de warfe for niet kunnen vertellen.

Uw film is niet thematisch opgebouwd. Was het moe likk om het fragmentarische aspect te behouden om niet in een narratief schema te vervallen?

Christophe Cognet: Dat was de absolute voorwaard om de film te maken. Tijdens de research werd dat al duidelijk. Ik wilde geen totaliserend uitgangspunt, en ook geen praxis van het tekenen in de kampen. Van alle werken die daar zijn gemaakt, zijn er maar weini teruggekomen. En van de werken die zijn teruggekois anders th er maar ence inche Bir van Birkenau, dat zijn twee verschillende dingen. Portretten maken van SS-families in Treblinka of, zoal Dina Gottliebova, schilderijen maken in opdracht van Mengele. opnieuw twee heel andere ervaringen. Toen Wet idennen te draaien, lag de montage nog niet vast. blijft in een spiraal rond die afgrond draaien.

Net zoals u de lijnen van de tekening volgt, zo filmt de takken van de bomen in het landschap.

Christophe Cognet: Ik wilde ze op dezelfde manier filmen, maar dat was niet eenvoudig, om twee redenen: ten eerste door de locaties. Ik zag meteen dat ik drin later alleen. Ik maakte dan geen foto's, met historicien tater notities. Dehele tijd had ik het gevoel dat ik de hoogte in moest om te filmen. In Birkenau hebben we twee dagen prikkeldraad uit te komen, en toen besefte ik dat die $\bullet$. 


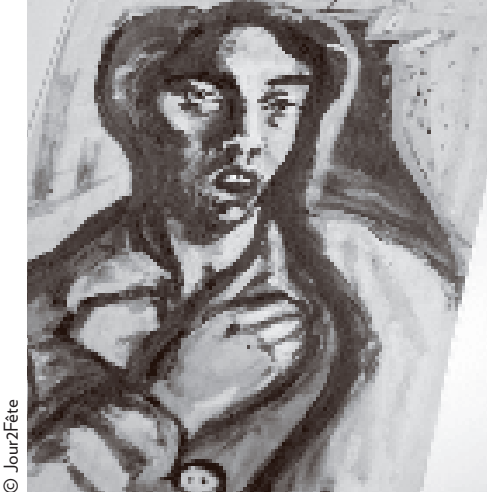

maakte bij zijn terugkeer. Praag, 1945.

œ kraan precies even hoog was als de toegangspoort.

De tweede reden voor die bewegende shots va het landschap is het schematische aspect van de tekening. In een tekening zoekt de kunstenaar lijnen en gedachten. Wanneer je in de modder ploetert, in dat jophoudelijke lawai, in dat geweld, dan probeer je te begrijpen waar je bent. Die behoefte om het van en tekenen biedt die mogelijkheid. In die zin moest de film de beweging van de tekening volgen.

Het corpus dat we kennen, bevat opvallend weinig tekeningen met een vogelperspectief. Aldo Carpi ging
op een uitkijktoren staan om een tekening te maken bij de bevrijding van Gtan

Christophe Cognet: De tekeningen die Goyard maakte Christophe Cognet: De tekeningen die Goyard maak van Buchenwald lijken daar sterk op. Roman Ieffimenk heeft ook een paar tekeningen gemaakt met een zich heuvel gar heuvel gaan staan om een overzicht te hebben, ee die behoefte om de dingen te overschouwen.

$\mathrm{U}$ toont meestal niet meteen de volledige tekening Bij Bacon en de Camarade mort van Delabre, helema an het einde van de film, beweegt u de camera langzaam over het werk om een bepaalde spanning te creëren voor het geheel wordt onthuld. De kijker verliest daarbij het Chis dimenie. ls dat een bewste keuze?

Christophe Cognet: Een aantal tekeningen zie je inel te maken van de plaats waar het werk zich bevindt, en daarn pas van het werk zelf. Anders gever of dehandenvan de kunstenaa wel een idee van de dimensie ning van Yehuda ik het verh vertellen. Ik film vertellen. Ikfilm een rechthoekige tekening van bovenaf in cinemascoop (met een beeldvekning vand tekening volledig had gefilmd
op deze manier, zou tachtig procent van het beeld leeg blijven. Bovendien wilde ik ook de dubbele dimensie je je de rande dubbele millimer van de rand, om 'in het verh n' te bij een millimeter van de rand, om 'in het verhaal' te blijven, kan ik het verhal van het werk niet vertellen.

\section{Het is dus een manier om een narratief element op} de tekening te projecteren.

. alleen tot zichzet: Alleenverhout de strueren Ik toon tekeningen in the vormaal te reconsoms zijnze helklein. Je to allo zen tijdens het draaien.

Welke rol heeft de emotie in uw film? Is het uw bedoeing om een bepaalde emotie op te wekken?

Christophe Cognet: Ik wilde geen pathos. De feiten preken voor zich. Het was totaal overbodig om terus te vallen op de traditionele beelden die we kennen van ekampen, met prikkeldraad op de voorgrond en vioolmuziek. Of te doen wat Spielberg doet in een aantal scènes van Schindler's List, wanneer hij bijvoorbeeld gevangenen opvoert die naar de douches stappen. Daarom ben ik zelf ook te zien in de film. Je ziet een lichaam, een persoon die de vragen stelt. Een soort van emiddelaar tussen kijker, camera en wat er word gefilmd, iemand die het onderzoek kan belichamen. Paradoxaal genoeg is dat een manier om niet in het pathetische af te glijden.

Als je filmt, schept je zowel nabijheid als afstand egenover je onderwerp. In die zin is het vergelijkbaar een manier om zich los te rukken van de wereld die ze afbeelden, terwijl ze er op die manier juist ook bewuster deel van gaan uitmaken. Dankzij de film kon ik me afschermen van overdreven sterke emoties, en voelde $\mathrm{k}$ me tegelijkertijd nauwer verbonden met al die tekeningen, plaatsen en gebeurtenissen.

Het shot van Birkenau in de sneeuw is prachtig, maa ook ongemakkelijk. Met deze opname tast u de grenzen ook ongemakkelijk. Met deze op

Christophe Cognet: Dan moet u weten dat ik bij het kalibreren van de film de lichteffecten nog heb afgezwakt. Die shots zijn gemaakt in absurde omstandigheden: we hadden geen geld meer. Ik zei tegen de digheden: we had ingen producer dat ik Birkenau in de sneeuw moest gaan

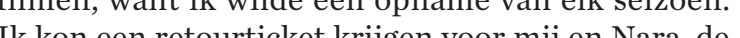
Ik kon een retourticket krijgen voor mije n Nara, de we $n$ vertick tijd gemaakt.

Kunnen we het nog even hebben over de werken van Gottliebova die in de film aan bod komen?

Christoph Cogn DinaGottilobovahadenel reproChristophe Cognet: Dina Gotlliebova had enkel reproducties van haar tekeningen, omdat het memoriaa werk dwingt ons om na te denken over den. Haar werk dwing ons on na te denken over de essentie van kunst. wat betekent het on auteur te zijn van een . materialen, noch de kleuren, noch het tijdstip hebt bepaald. Dat is problematisch. het staat zo ver af van voerder, zij heeft de tekeningen voerder, zij heeft de tekeningen gemaakt, en dus heeft zeen be Ze had de tentoonstelling van haar werk kunnen verbieden. Ik vind het zelf heel moeilijk om hier de gren te trekken. wanneer is iets kunst, wanneer is het een stukgeschiedenis. We heb op de zigeuners. Eigenlijk hor we tekeningen thuis in een zigeunermemoriaal. Ze zijn trouwens te zie in het zigeunerpaviljoen van Ausc ch gezien de eigenaar?

Bestaat er een verschil tussen clandestiene werken en werken die in opdracht zijn gemaakt?

fundanented Christophe Cognet: Jazeker, er is een fundamente verschil. Een SS-kind porttetteren, dat was toegeIn het tweede geval voel je de urgentie, in het eerst eval probeerde de tekenaar zo lang mogelijk aan het portret te werken om het warm te hebben. Mensen ebren hun levente danken aan hun tekenkunsten dat vertelt Maurice de la Pintière ons. Hij was zich aan het doodwerken in de Dorafabriek toen zijn kapo vroeg of een kunstenaar was in zijn blok. 'Ja, ik', antwoordde hij, en de kapo droeg hem op het blok te schilderen. $\mathrm{Hij}$ maakte een fresco: Sneeuwwitje en de zeven dwergen. ij had het warm. Volgens hem heeft dat zijn leven gered.

U zegt dat u zich inspireert op Bruegel. Hoe verhoud uw werk zich tot de schilderkunst?

Chis uws, en proberen datinverband te brengen met wat ze al ken rect be de binnenknt van een gaskail certelde me dat cultuur een lens is wardoorje dingen rijkt. De retatie tusen film en schild a c disen kijkt. De relatie tussen fils en schilderkunst is er geen van gelijkenis. Als ik film, zie ik vormen. . etzor je dist scheriste: ser

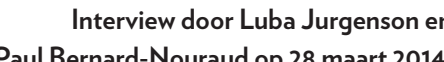
$\rightarrow$ Meer info

$\diamond$ Parce que jétais peintre. L'art rescapé des camps nazis, [lk was tenslotte schilder. Kunst die de nazikampen overleefde
van Christophe Cognet, lu44, La Huit Production, 2013. De film werd geselecteerd voor het Internationale filmfestiv van Rome in 2013 en kwam uit op 5 maart 2014
(1) Lees ook de biografie van Spitzer.

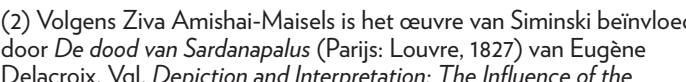
Delacroix. Vgl. Depiction and Interpretation: The Influence of the
Holocaust on Visual Arts, Londen: Pergamon, 1993, 45.

(3) Madrid: Prado, 1562 